\title{
Performance of Density Functional Theory for Transition Metal Oxygen Bonds
}

\author{
Moltved, Klaus August; Kepp, Kasper Planeta
}

Published in:

ChemPhysChem

Link to article, DOI:

$10.1002 /$ cphc. 201900862

Publication date:

2019

Document Version

Peer reviewed version

Link back to DTU Orbit

Citation (APA):

Moltved, K. A., \& Kepp, K. P. (2019). Performance of Density Functional Theory for Transition Metal Oxygen Bonds. ChemPhysChem, 20(23), 3210-3220. https://doi.org/10.1002/cphc.201900862

\section{General rights}

Copyright and moral rights for the publications made accessible in the public portal are retained by the authors and/or other copyright owners and it is a condition of accessing publications that users recognise and abide by the legal requirements associated with these rights.

- Users may download and print one copy of any publication from the public portal for the purpose of private study or research.

- You may not further distribute the material or use it for any profit-making activity or commercial gain

- You may freely distribute the URL identifying the publication in the public portal

If you believe that this document breaches copyright please contact us providing details, and we will remove access to the work immediately and investigate your claim 


\section{A EUROPEAN JOURNAL}

\section{CHEMPHYSCHEM}

OF CHEMICAL PHYSICS AND PHYSICAL CHEMISTRY

\section{Accepted Article}

Title: Performance of Density Functional Theory for Transition Metal Oxygen Bonds

Authors: Klaus August Moltved and Kasper Planeta Kepp

This manuscript has been accepted after peer review and appears as an Accepted Article online prior to editing, proofing, and formal publication of the final Version of Record (VoR). This work is currently citable by using the Digital Object Identifier (DOI) given below. The VoR will be published online in Early View as soon as possible and may be different to this Accepted Article as a result of editing. Readers should obtain the VoR from the journal website shown below when it is published to ensure accuracy of information. The authors are responsible for the content of this Accepted Article.

To be cited as: ChemPhysChem 10.1002/cphc.201900862

Link to VoR: http://dx.doi.org/10.1002/cphc.201900862 


\section{Performance of Density Functional Theory for Transition Metal Oxygen Bonds}

Klaus A. Moltved and Kasper P. Kepp*

Technical University of Denmark, DTU Chemistry, Building 206, 2800 Kgs. Lyngby, DK Denmark.

* Corresponding author: Phone: +045 452524 09. E-mail: kpj@kemi.dtu.dk 


\begin{abstract}
The accuracy of Density functional theory (DFT) limits predictions in theoretical catalysis, and strong chemical bonds between transition metals and oxygen pose a particular challenge. We benchmarked 30 diverse density functionals against the bond dissociation enthalpies (BDE) of the $30 \mathrm{MO}$ and $30 \mathrm{MO}^{+}$diatomic systems of all the $3 \mathrm{~d}, 4 \mathrm{~d}$, and $5 \mathrm{~d}$ metals, to test universality across the d-block as required in comparative studies. Seven functionals, B98, B97-1, B3P86, B2PLYP, TPSSh, B3LYP, and B97-2, display mean absolute errors (MAE) < $30 \mathrm{~kJ} / \mathrm{mol}$. In contrast, many commonly used functionals such as PBE and RPBE overestimate M-O bonding by $+30 \mathrm{~kJ} / \mathrm{mol}$ and display MAEs from 48-76 kJ/mol. RPBE and OPBE reduce the over-binding of PBE but remain very inaccurate. We identify a linear relationship (p-value $7.6 \cdot 10^{-5}$ ) between the precision and accuracy of DFT, i.e. inaccurate functionals tend to produce larger, unpredictable random errors. Some functionals commonly deviate from this relationship: Thus, M06-2X is very precise but not very accurate, whereas B3LYP* and MN15-L are more accurate but less precise than M06-2X. The best-performing hybrids have 10-30\% HF exchange, but this can be relieved by double hybrids (B2PLYP). Most functionals describe trends well, but errors comparing $5 \mathrm{~d}$ to $4 \mathrm{~d} / 3 \mathrm{~d}$ are $\sim 10 \mathrm{~kJ} / \mathrm{mol}$ larger than group-wise errors, due to uncertainties in the spin-orbit coupling corrections for effective core potentials, affecting e.g. $\mathrm{Pt} / \mathrm{Pd}$ or $\mathrm{Au} / \mathrm{Ag}$ comparisons.
\end{abstract}

\title{
Keywords: DFT, transition metals, oxygen, catalysis, bond dissociation enthalpy
}




\section{Introduction}

Chemical bonds between d-transition metals and oxygen play a central role in mineralogy ${ }^{[1-4]}$, biological management of oxygen by iron and copper, ${ }^{[5-8]}$ and chemical catalysis ${ }^{[9-12]}$, including numerous energy-related applications ${ }^{[13-16]}$, specific examples being metal-catalyzed water splitting $^{[17]}$, conversion of methane to methanol ${ }^{[18]}$, and epoxidations. ${ }^{[19]}$

The simplest possible transition metal oxygen system is the diatomic molecule (MO), which in a pure way probes the ability of the metal (M) to bond to oxygen, without any modulating, potentially noisy effects from other ligands or metals in a catalytic or chemical system. These systems have long been important as benchmark systems for theory ${ }^{[20-22]}$, in astrochemistry, high temperature inorganic chemistry, and spectroscopy ${ }^{[23,24]}$. Major interest in them has emerged with the increasing focus on very small catalytic systems approaching the limit of single-atom catalysts which can exhibit many-fold increased efficiency relative to conventional catalysts ${ }^{[11,25,26]}$.

Inspired by the push towards minimal catalytic systems, we envision a de novo approach to catalysis starting from the "minimal catalytic units" such as MO, and rationally adding components in a fully understood manner to reach the complete, tailored catalyst. We expect that complete insight into the electronic structure of the minimal catalytic units such as $\mathrm{M}, \mathrm{MO}, \mathrm{MO}_{2}$, and $\mathrm{M}_{2} \mathrm{O}_{2}$ enables the building of the maximally efficient catalyst by adding chemical components bottom-up. The success largely relies on the observation that many chemical properties of small molecules are periodic, leading e.g. to the early concept of a periodic table of diatomics ${ }^{[27-29]}$.

A major advantage of this strategy is the existence of many more systematic experimental data for small molecular systems than for larger homogeneous and heterogeneous catalytic systems. For the diatomic $\mathrm{MO}$ and $\mathrm{MO}^{+}$systems studied in this work, almost all of the 60 bond dissociation enthalpies (BDE) are available for all the $3 \mathrm{~d}, 4 \mathrm{~d}$, and $5 \mathrm{~d}$ systems, enabling full account of the periodicities and trends needed for rational catalyst design ${ }^{[30]}$. In contrast, experimental data for larger catalytic systems are very protocol-dependent, ${ }^{[31]}$ they are incomplete along the $3 \mathrm{~d}$, $4 \mathrm{~d}$, and 
5d series and are sensitive to defects, solid crystal structure, surface coverage, solvent, $\mathrm{pH}$, and temperature. Even if experiments could sort out these confounding system-and condition-dependent factors, it is beyond the capability of current theoretical methods to model these effects accurately, producing likely random errors of the order of $20-50 \mathrm{~kJ} / \mathrm{mol}$, in addition to the errors in the functional itself, the thermodynamic and relativistic corrections, and the dispersion effects. ${ }^{[32]}$ Claims of higher accuracy than $30 \mathrm{~kJ} / \mathrm{mol}$ between DFT and data such as chemisorption energies on surfaces should thus be considered with substantial skepticism. Fortunately, some errors are systematic and affect different systems in the same direction, inducing partial cancellation of the systematic errors in comparisons, which is good enough for catalyst design but not for understanding the processes absolutely.

For small systems, accurate quantum-chemical methods can compute the energies of bond formation and bond breaking, which enables a test of the accuracy of DFT methods used for specific systems. In particular, the use of the BDEs of metal-ligand bonds are receiving significant attention as best-practice benchmark properties for chemical reactivity across the d-block ${ }^{[30,33-40]}$. The success largely relates to the fact that the diatomic M-O BDEs correlate better than any other known single descriptor to the chemisorption energies of pure metal surfaces, with $\mathrm{R}^{2}$ approaching 0.89 when computed with the same methods ${ }^{[30]}$, across a range of more than $500 \mathrm{~kJ} / \mathrm{mol}$ in both $\mathrm{O}_{2}$ chemisorption energies and M-O BDEs within the d-block. Coordinative saturation, metal-metal modulations and solvent effects contribute smaller errors to the DFT-modelled process than the local M-O bond, because the relative M-O bond energies vary by an order of magnitude more than the metal-metal modulating influences, or correspondingly, the trend in cohesive energy changes upon ligand dissociation from different metal surfaces. Diatomic M-O BDEs display a residual error of $46 \mathrm{~kJ} / \mathrm{mol}$ against full surface chemisorption energies when computed with the same method ${ }^{[30]}$, i.e. the total modulating effects contribute less than $46 \mathrm{~kJ} / \mathrm{mol}$ to the trend prediction, consistent with the smaller variations in enthalpies of metal atomization relative to M-O bond energies. For comparison, PBE itself has an MAE of $76 \mathrm{~kJ} / \mathrm{mol}$ for the M-O BDEs, as shown below. 
We recently ${ }^{[30]}$ established a data set of curated experimental BDEs for diatomic transition metal oxides, using experimental trends and state-of-the-art $\operatorname{CCSD}(\mathrm{T})$ computations, which reproduce experimental values excellently ${ }^{[30]}$. We have also shown how $\operatorname{CCSD}(\mathrm{T})$ can be used to evaluate full, simple catalytic cycles ${ }^{[41]}$, again utilizing the fact that the energy errors of the bonds broken and formed during catalysis dominate the energies of the overall catalytic reaction and thus the errors of theoretical catalysis. Using such "full-cycle benchmarking",[41], the difficulty of modeling each step of a process with DFT can be assessed directly. It turns out, unfortunately, that different density functionals have problems with different steps of a catalytic cycle due to their distinct electronic changes, with particular problems emerging in the non-universality of DFT when simultaneously studying early and late transition metals ${ }^{[40]}$, metals with variable coordination number ${ }^{[39]}$, and metals with variable types of ligands binding ${ }^{[40]}$, with particular problems arising for self-interaction-error-prone metal-hydrogen bonds. ${ }^{[39,41]}$

Although progress in the use of coupled-cluster theories to larger systems is promising and will accelerate de novo strategies ${ }^{[42,43]}$, they remain too computationally demanding for larger catalytic systems. Accordingly, in this work we benchmark the ability of state-of-the-art DFT to describe the $\mathrm{MO}$ and $\mathrm{MO}^{+} \mathrm{BDEs}$, using curated experimental data set that include 28 of the 30 possible neutral diatomic MO molecules and 27 of the 30 possible diatomic cationic $\mathrm{MO}^{+}$systems of the $3 \mathrm{~d}, 4 \mathrm{~d}$, and $5 \mathrm{~d}$ transition metal series ${ }^{[30]}$. Importantly, these data do not suffer from errors due to the modeling of solvent, dispersion, and entropy effects as they are gas phase enthalpies with dispersion effects substantially smaller than $1 \mathrm{~kJ} / \mathrm{mol}^{[40]}$, and the data set is balanced across the $3 \mathrm{~d}$, $4 \mathrm{~d}$, and $5 \mathrm{~d}$ metals and thus prevents system-biased conclusions common to many studies of both large and many small systems with over-representation of some $n \mathrm{~d}^{\mathrm{q}}$ electronic configurations. ${ }^{[39,40]}$

Many of the 60 diatomic systems have been studied before at various levels of theory ${ }^{[20,21,46-}$ $50,22,23,30,34,35,40,44,45]$. However, this paper presents the first systematic benchmark of DFT for all 3d, 4d, and $5 \mathrm{~d} \mathrm{MO}$ and $\mathrm{MO}^{+}$systems as required to evaluate system dependencies and universality across the groups and periods of the d-block. To probe DFT broadly, we compared 30 different 
diverse functionals, including local, gradient-corrected, local and global hybrids, meta functionals and range-separated functionals, giving the most systematic and complete picture so far of the ability of DFT to describe M-O bonds. 


\section{Methods}

Experimental data. Based on analysis of the trends of experimental BDEs, a recommended experimental data set for BDEs of $\mathrm{MO}$ and $\mathrm{MO}^{+}$systems was established in previous work(Table S1) ${ }^{[30]}$. The data set contains BDEs for 55 of the 60 systems and is well-balanced across all three dtransition metal periods and groups.

Computational details. All computations were performed with the Turbomole software, version $7.0^{[51]}$ and the Gaussian $16^{[52]}$ software. All computations were performed using unrestricted Kohn Sham orbitals without symmetry (C1 point group). BDEs were calculated for the 30 neutral M-O and 30 cationic $\mathrm{M}^{+}-\mathrm{O}$ systems of the $3 \mathrm{~d}, 4 \mathrm{~d}$ and $5 \mathrm{~d}$ transition metals (Sc-Zn, Y-Cd and LaHg). BP86/def2-TZVPP optimized geometries were taken from our previous work ${ }^{[30]}$ (Table S2) and used for all energy calculations. This method provides some of the best geometries for these systems, with average errors below $0.02 \AA^{[30]}$. For 15 of the diatomic molecules, experimental bond lengths are available (Table S3). To ensure that BDEs and conclusions are not sensitive to reasonable variations in geometry, we computed the B3LYP single-point energies of these 15 systems both at the experimental and optimized geometry (Tables S4-S5). As seen, the energy is affected by less than $1 \mathrm{~kJ} / \mathrm{mol}$ in all cases except $\mathrm{LaO}(8 \mathrm{~kJ} / \mathrm{mol})$ which is a particular difficult system. Considering that the BDEs span from 100-800 kJ/mol (Table S1) and errors exceed 25 $\mathrm{kJ} / \mathrm{mol}$, the uncertainties in geometry do not contribute substantially to the results and conclusions presented below.

Zero-point energies (ZPE), relativistic corrections to electronic energies, and used spin states for the 60 diatomics were taken from previous work where these parameters were carefully evaluated against the best experimental data and $\operatorname{CCSD}(\mathrm{T})^{[30]}$. Thus, for example, the previously observed uniform accuracy of $\operatorname{CCSD}(\mathrm{T})$ across the $3 \mathrm{~d}, 4 \mathrm{~d}$, and $5 \mathrm{~d}$ series shows that the applied spin orbit coupling and scalar relativistic corrections capture accurately (errors of $\sim 5 \mathrm{~kJ} / \mathrm{mol}$ ) the full dblock as a whole as required for DFT applications across all three periods ${ }^{[30,40]}$. For convenience 
these corrections are summarized in the supporting information Tables S6-S9. The ground state spin states for atoms and atomic ions used for computation were taken from NIST ${ }^{[53]}$ and can be found in Table S10.

Single point DFT energies. Single point energies were computed using the 30 density functionals of Table 1, with references, functional type, HF exchange percentage, and software used (Gaussian or Turbomole) given. These 30 functionals include many of the most popular used in computational chemistry and theoretical catalysis such as PBE, RPBE, and B3LYP, but also many newer functionals and representing all the major classes of design type. The basis set used for singlepoint energies was def2-QZVPPD ${ }^{[54]}$ for the metals (Sc-Zn, Y-Cd and La-Hg) and aug-cc-pV5Z ${ }^{[55]}$ for the very electronegative oxygen. This basis set is saturated to within $2-3 \mathrm{~kJ} / \mathrm{mol}$ in terms of errors in BDEs as shown from previous work ${ }^{[40,56]}$.

Calculation of BDEs. The BDEs were calculated from the computed electronic energies as:

$$
B D E(M-O)=E(M)+E(O)-E(M O)-E_{Z P E}+E_{\text {scalar }}+E_{S O C}+3.7 \mathrm{~kJ} / \mathrm{mol}(1)
$$

Here, $E(M), E(O)$ and $E(M O)$ are the electronic energies of the metal, oxygen atom, and MO or $\mathrm{MO}^{+}$molecule, as tabulated in Tables S11-S20. $E_{Z P E}$ is the computed zero-point energy of the molecule (Table S7). $E_{\text {scalar }}$ is the scalar-relativistic energy correction (Table S8), $E_{S O C}$ is the computed spin orbit coupling (SOC) correction (Table S9), and $3.7 \mathrm{~kJ} / \mathrm{mol}$ corresponds to 3/2 RT at $298 \mathrm{~K}$ which converts the BDEs from $0 \mathrm{~K}$ to $298 \mathrm{~K}$. The $60 \mathrm{BDEs}$ calculated for the 30 functionals (1800 BDE values in total) are compiled in Tables S21-S25. Signed errors (SE) were calculated according to Equation 2:

$$
S E=B D E(M O)_{\text {comput }}-B D E(M O)_{\text {exp }}
$$

where $B D E(M O)_{\text {comput }}$ is the BDE calculated from Equation 1, and $B D E(M O)_{\text {exp }}$ is the experimental BDE from Table S1. The absolute errors (AE) reported in this work are the absolute values of the SE, whereas the mean signed errors (MSE) and mean absolute errors (MAE) discussed 
below are the averages of the SE and AE, respectively; these errors for the full data set are summarized in Table S26 and in Table S27 (exclusing the main outlier, $\mathrm{LaO}^{+}$). Tables S28-S40 show errors for various subsets of the overall data set to test the sensitivity of results to variations in the data by dividing them into groups and periods, and $\mathrm{MO}$ vs. $\mathrm{MO}^{+}$systems. The overall five largest errors for all functionals are compiled in Table S41, whereas Table $\mathbf{S 4 2}$ shows the properties of the linear regression analysis. 
Table 1. 30 Exchange-correlation functionals used in this work, with references, amount of HFexchange, functional type and program used for calculations.

\begin{tabular}{|c|c|c|c|c|}
\hline Functional & Type & $\% \quad \mathrm{HF}$ & References & Software \\
\hline APFD & Hybrid GGA & 23 & \begin{tabular}{l|l}
$57]$ \\
\end{tabular} & Gaussian16 \\
\hline B2PLYP & Double Hybrid & 53 & {$[58]$} & Turbomole \\
\hline B3LYP & Hybrid GGA & 20 & {$[59-61]$} & Turbomole \\
\hline B3LYP* & Hybrid GGA & 15 & {$[59-61]$} & Turbomole \\
\hline B3P86 & Hybrid GGA & 20 & {$[62,63]$} & Turbomole \\
\hline B97-1 & Hybrid GGA & 21 & {$[64]$} & Gaussian16 \\
\hline B97-2 & Hybrid GGA & 21 & {$[65]$} & Gaussian16 \\
\hline B97-D & GGA & 0 & [66] & Gaussian16 \\
\hline B98 & Meta hybrid & 22 & [67] & Gaussian 16 \\
\hline BHLYP & Hybrid GGA & 50 & {$[68]$} & Turbomole \\
\hline BLYP & GGA & 0 & {$[62,63]$} & Turbomole \\
\hline BP86 & GGA & 0 & {$[62,63]$} & Turbomole \\
\hline CAM-B3LYP & Range-separated & $19-65$ & [69] & Gaussian 16 \\
\hline HSE06 & Range-separated & $0-25$ & {$[70-76]$} & Gaussian 16 \\
\hline M06 & Meta hybrid & 27 & [77] & Gaussian16 \\
\hline M06-2X & Meta hybrid & 54 & [77] & Turbomole \\
\hline M06-L & Meta GGA & 0 & {$[78]$} & Gaussian16 \\
\hline MN15 & Meta hybrid NGA & 44 & [79] & Gaussian16 \\
\hline MN15-L & Meta NGA & 0 & {$[80]$} & Gaussian16 \\
\hline O3LYP & Hybrid GGA & 12 & [81] & Gaussian 16 \\
\hline OLYP & GGA & 0 & {$[60,82]$} & Turbomole \\
\hline OPBE & GGA & 0 & {$[83,84]$} & Turbomole \\
\hline PBE & GGA & 0 & [84] & Turbomole \\
\hline PBEO & Hybrid GGA & 25 & {$[84,85]$} & Turbomole \\
\hline PW6B95 & Meta hybrid & 28 & {$[86]$} & Turbomole \\
\hline RPBE & GGA & 0 & [87] & Turbomole \\
\hline SVWN & LSDA & 0 & {$[88,89]$} & Turbomole \\
\hline TPSS & Meta GGA & 0 & {$[90]$} & Turbomole \\
\hline TPSSh & Meta hybrid & 10 & [90] & Turbomole \\
\hline wB97XD & Range-separated & $22-100$ & [91] & Gaussian 16 \\
\hline
\end{tabular}




\section{Results and Discussion}

Accuracy and precision of density functionals. Figure 1A and Figure 1B show the mean absolute error (MAE) and mean signed error (MSE) for the 30 functionals describing the BDEs of Table 1. The MAEs describe the overall absolute accuracy of the functionals and the MSEs describe the accuracy in terms of systematic over- or under-binding; a negative value implies under-binding, and a positive value implies over-binding. We also speculated that the precision of DFT applied to M$\mathrm{O}$ bonds is of interest in addition to the normally assessed accuracy. The precision tells us about the spread in estimated values regardless of how accurate the numbers are. We estimated the precision from the standard deviation (STD) of the SE, which is shown as black lines in Figure 1B.

From Figure 1A, the MAE ranges from 26 to $178 \mathrm{~kJ} / \mathrm{mol}$ and the MSE from -121 (BHLYP) to +178 (SVWN) kJ/mol. The STD can be found in Table $\mathbf{S 2 6}$ and ranges from $33 \mathrm{~kJ} / \mathrm{mol}$ to 56 $\mathrm{kJ} / \mathrm{mol}$. The most accurate functional B98 also has an acceptable MSE of $-8 \mathrm{~kJ} / \mathrm{mol}$ and a STD of the SE of $34 \mathrm{~kJ} / \mathrm{mol}$, i.e. the functional is expected to produce an SE of $-8 \pm 34 \mathrm{~kJ} / \mathrm{mol}$ for $68 \%$ of the studied MO BDEs, assuming a normal distribution of the errors. Considering that $\operatorname{CCSD}(\mathrm{T})$ with the same type of vibrational and relativistic corrections has a MAE of $25 \mathrm{~kJ} / \mathrm{mol}$ and MSE of $3 \pm 32$ $\mathrm{kJ} / \mathrm{mol}$ for the same data, ${ }^{[30]}$ the performance of the best functionals is almost on level with $\operatorname{CCSD}(\mathrm{T})$, which is highly encouraging. Since the average experimental uncertainty is $\sim 17 \mathrm{~kJ} / \mathrm{mol}$ for the data where these uncertainties are reported (assuming similar uncertainty for the remaining data) a "perfect" method can never achieve a MAE smaller than $~ 20 \mathrm{~kJ} / \mathrm{mol}$, and we note that several of the best functionals perform not far from this threshold. 

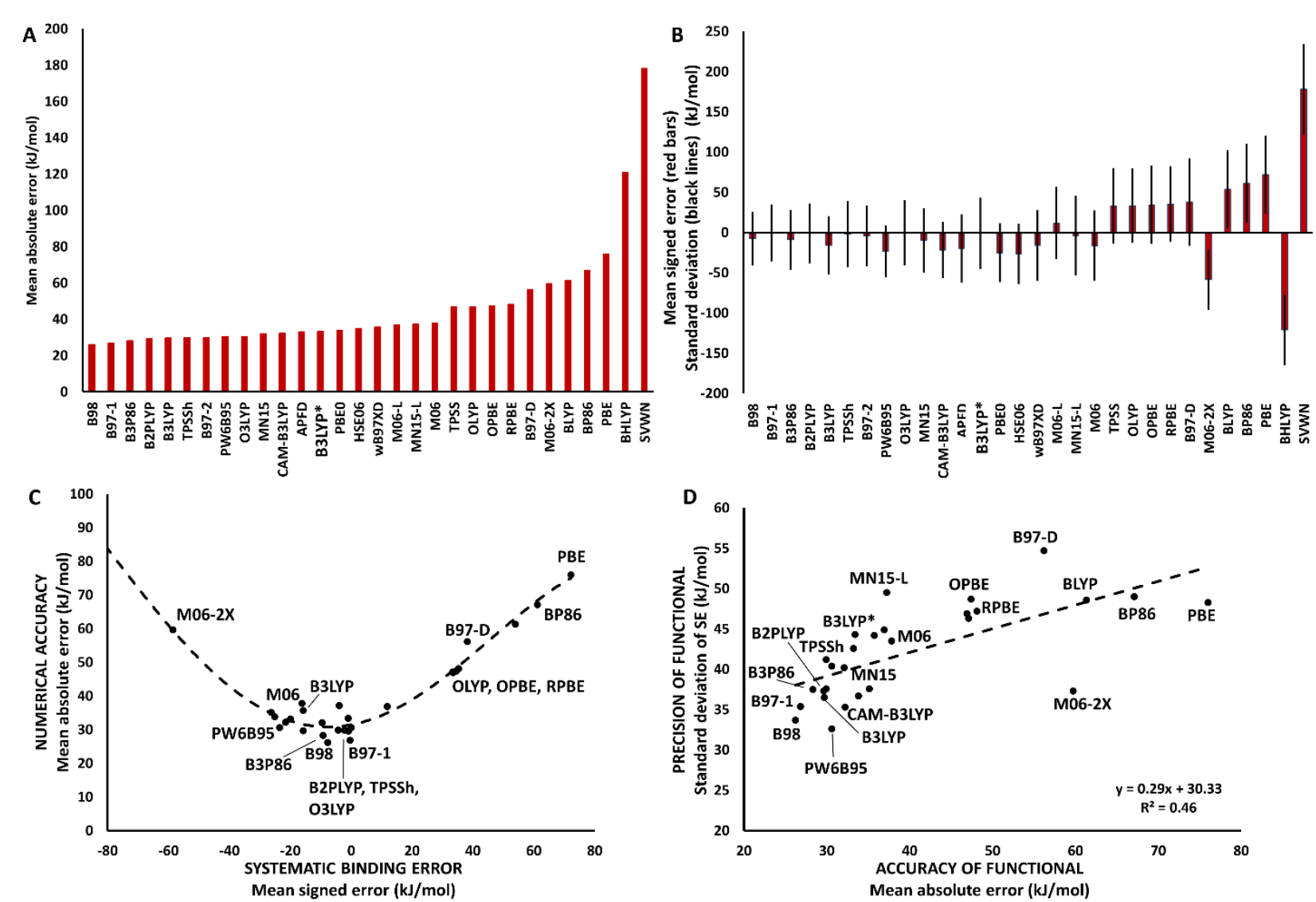

Figure 1. A) Mean absolute error (MAE) B) Mean signed error (MSE) (red bars), for the 30 functionals of Table 1. The black lines show the standard deviation of the error. C) Relation between overall numerical accuracy as measured by MAE and systematic binding error as measured by MSE. D) Relation between precision (measured as standard deviation of the error) and accuracy (measured as MAE) of the functionals. Tabulated errors are available in Table S26.

The most accurate functionals measured by the MAE of Figure 1A are B98, B97-1, B3P86, B2PLYP, B3LYP, TPSSh, and B97-2, with MAEs of between 26 and $30 \mathrm{~kJ} / \mathrm{mol}$, MSEs between -16 and $0 \mathrm{~kJ} / \mathrm{mol}$, and standard deviations of the errors of $34-37 \mathrm{~kJ} / \mathrm{mol}$ (Figure 1B). These functionals are all hybrids. B98, B97-1, B3P86 and B3LYP have 22, 21, 20 and 20\% HF-exchange, respectively, whereas TPSSh is a meta-hybrid with $10 \%$ HF exchange. This meta-hybrid requires less HF-exchange to be accurate, possibly due to its kinetic energy gradient. It is notable that the MSE and MAE are not always fully correlated, and thus some functionals, e.g. B3LYP, have a surprisingly low MAE despite a consistent tendency to under-bind. Because of the substantial 
diversity of the 30 investigated functionals, such variations are expected. B98, B97-1 and B2PLYP have previously ${ }^{[92]}$ been found to predict the thermochemistry for $3 \mathrm{~d}$ transition metal species excellently, as is also the case for the transition metal oxides (Figure 1A and 1B). The success of the B98, B97-1 and B97-2 functionals is remarkable considering that their parameterization was based on the G2 test set or slight modifications thereof ${ }^{[64,65,67]}$.

The good performance of B2PLYP with 53\% HF exchange shows that the "requirement" of 10-20\% HF exchange can be relaxed by compensating correlation energy from MP2 perturbation theory, which works very well. The performance of B2PLYP for the M-O bonds of both 3d, 4d, and $5 \mathrm{~d}$ transition metals is promising as this functional is also accurate for both coordinately saturated and unsaturated $\mathrm{M}-\mathrm{H}$ bonds, which are intrinsically hard to model simultaneously with a global hybrid or GGA. ${ }^{[39]}$ Since theoretical catalysis requires uniform accuracy across both $3 \mathrm{~d}, 4 \mathrm{~d}$, and $5 \mathrm{~d}$ systems, often involves both hydrogen and non-hydrogen ligands and common changes in coordination number at the metal site, we recommend B2PLYP for use in d-transition metal catalysis due to its uniform (transferable) high accuracy and precision. Other well performing functionals are the meta hybrids PW6B95 (12\% HF exchange) and MN15 (44\%). It is interesting that the higher-order derivatives included in the more mathematically complex meta functionals reduce the need for HF exchange. Kulik and co-workers have noticed a similar effect on spin state energies $^{[93]}$, favoring the more atomic state (weakening bonding and favoring higher spin), which is also the reason why TPSSh (10\%) commonly performs similar to the 15\%-HF hybrid B3LYP*[94,95]. The good performance of MN15 with 44\% HF-exchange probably relates to is careful parametrization vs. data that include metal-ligand bond strengths ${ }^{[79]}$.

The performance of the range-separated hybrid CAM-B3LYP is also reasonable (Figure 1A, 1B). In contrast to many global hybrids and meta functionals, this range-corrected functional performs well for both unsaturated and saturated transition metal systems ${ }^{[39]}$ and for spin splitting energies $^{[96]}$. It is notable that the more complex double hybrids and range-separated hybrids uniquely show ability to model all these types of bonds as required for an accurate theoretical catalysis. 
Energetic effects of varying the HF exchange fraction in global hybrids is commonly linear, with high HF fraction causing under-binding and low HF fraction leading to stronger bonds ${ }^{[97,98]}$. For BHLYP, B3LYP, B3LYP*, and BLYP, the MSEs are -122, -16, -1, and $54 \mathrm{~kJ} / \mathrm{mol}$, respectively. This shows that an increase of $1 \%$ HF-exchange affects the MSE by approximately $3 \mathrm{~kJ} / \mathrm{mol}$, which is typical also for the high-spin low-spin energy gaps. ${ }^{[96]}$ A similar conclusion can be drawn when looking at the TPSS (0\% HF) and TPSSh (10\% HF) functionals where the MSE changes from -2 to $33 \mathrm{~kJ} / \mathrm{mol}$. For the PBE functional, the HF exchange dependence is slightly stronger, ca. $4 \mathrm{~kJ} / \mathrm{mol}$ per $1 \%$ HF exchange as estimated from PBE0 and PBE.

Unfortunately, all the GGA functionals studied in this work, including many commonly used in computational chemistry and catalysis, display MAEs from 37 and up to $76 \mathrm{~kJ} / \mathrm{mol}$. Notably, the PBE functional over-binds massively, giving a very large MSE of $72 \mathrm{~kJ} / \mathrm{mol}$ and a MAE of 76 $\mathrm{kJ} / \mathrm{mol}$. This fits well with results by Duanmu and Truhlar finding errors for oxygen chemisorption energies on four metal surfaces of $25-80 \mathrm{~kJ} / \mathrm{mol}$, with consistent tendency to over-binding ${ }^{[99]}$. This confirms our previous findings that both total energies and errors of the diatomic M-O systems and the full pure surfaces are very strongly correlated for a large number of data across the $3 \mathrm{~d}$, $4 \mathrm{~d}$, and $5 \mathrm{~d}$ periods $\left(\mathrm{R}^{2} \sim 0.89 \text { for } \mathrm{PBE}\right)^{[30]}$, and thus our analysis is very relevant to the large systems, and at much larger data coverage. Using the modified RPBE improves the MAE to $48 \mathrm{~kJ} / \mathrm{mol}$ and MSE to $35 \mathrm{~kJ} / \mathrm{mol}$, which is however still far from accurate. Studies using PBE and RPBE for transition metal oxygen bonds are thus likely to substantially over-bind oxygen and overestimate the metal's ability to bind and activate oxygen. If these studies are insightful, it is only when they compare different metals without emphasizing the absolute bonding, since the relative BDEs are more accurate than the absolute BDEs, as illustrated later in this paper. The local density functional SVWN was included for completeness as a reference point, which is mainly of theoretical interest as a limit of DFT, but which is still used. As expected ${ }^{[32,40]}$ SVWN over-binds massively with an MAE and MSE of $178 \mathrm{~kJ} / \mathrm{mol}$. 
Figure 1C shows the relation between the overall accuracy of the functional, as measured by the MAE, and its systematic error in terms of over- or under-binding, measured by the MSE. MAEs display a minimum at around $25 \mathrm{~kJ} / \mathrm{mol}$ as discussed above. Mostly, the best functionals in terms of MAE also have the smallest systematic errors, as visualized by the third-order polynomial fitting line which, in contrast to a second-order polynomial, condenses the MAEs near the hard limit of $\sim 25 \mathrm{~kJ} / \mathrm{mol}$ determined mainly by the random experimental errors. Accordingly, we have good coverage of both under-binding and over-binding functionals. We can also identify functionals for which systematic errors do not follow the expected trend. Notable examples are M06 and B3LYP. We expect a "universal" functional to approach zero MAE and MSE uniformly. It is also interesting that two of the best-performing functionals in terms of MAE, B98 and B3P86, systematically underbind with MSEs of $-7.7 \mathrm{~kJ} / \mathrm{mol}$ and $-9.2 \mathrm{~kJ} / \mathrm{mol}$, respectively, whereas B97-1 (MSE $=-0.4 \mathrm{~kJ} / \mathrm{mol}$ ) has almost no tendency to systematically under-bind or over-bind (unsigned MSEs smaller than 5 $\mathrm{kJ} / \mathrm{mol}$ are not significant due to the general uncertainty of the experimental data).

Figure 1D shows the relation between the precision, measured as the standard deviation of the signed errors, and the accuracy measured by MAE. We can postulate that the universal functional will have maximal precision and accuracy. To support this postulate, we find a significant linear relationship $\left(\mathrm{R}^{2}=0.46, \mathrm{p}=7.64 \cdot 10^{-5}\right)$ between the precision and the accuracy of the density functionals, using these definitions. This relationship is important, because it shows that as functionals become more accurate, they mostly tend to become more precise in their predictions. However, the relation is far from perfect, and there are clear outliers in Figure 1D mainly for heavily or dispersion-parameterized functionals or meta functionals. For example, M06-2X is very inaccurate for this dataset (MAE $\sim 60 \mathrm{~kJ} / \mathrm{mol}$ ) but has a high precision ( $\mathrm{STD}=37 \mathrm{~kJ} / \mathrm{mol}$ ), whereas MN15-L is fairly accurate $(\mathrm{MAE}=37 \mathrm{~kJ} / \mathrm{mol}$ ) but very imprecise, with a large scatter of BDE values $(\mathrm{STD}=50 \mathrm{~kJ} / \mathrm{mol})$. B3LYP* is another example of a functional that breaks the relationship, being less precise than its accuracy would imply. Whether these tendencies hold more generally beyond the data studied here needs to be explored. 
A 300

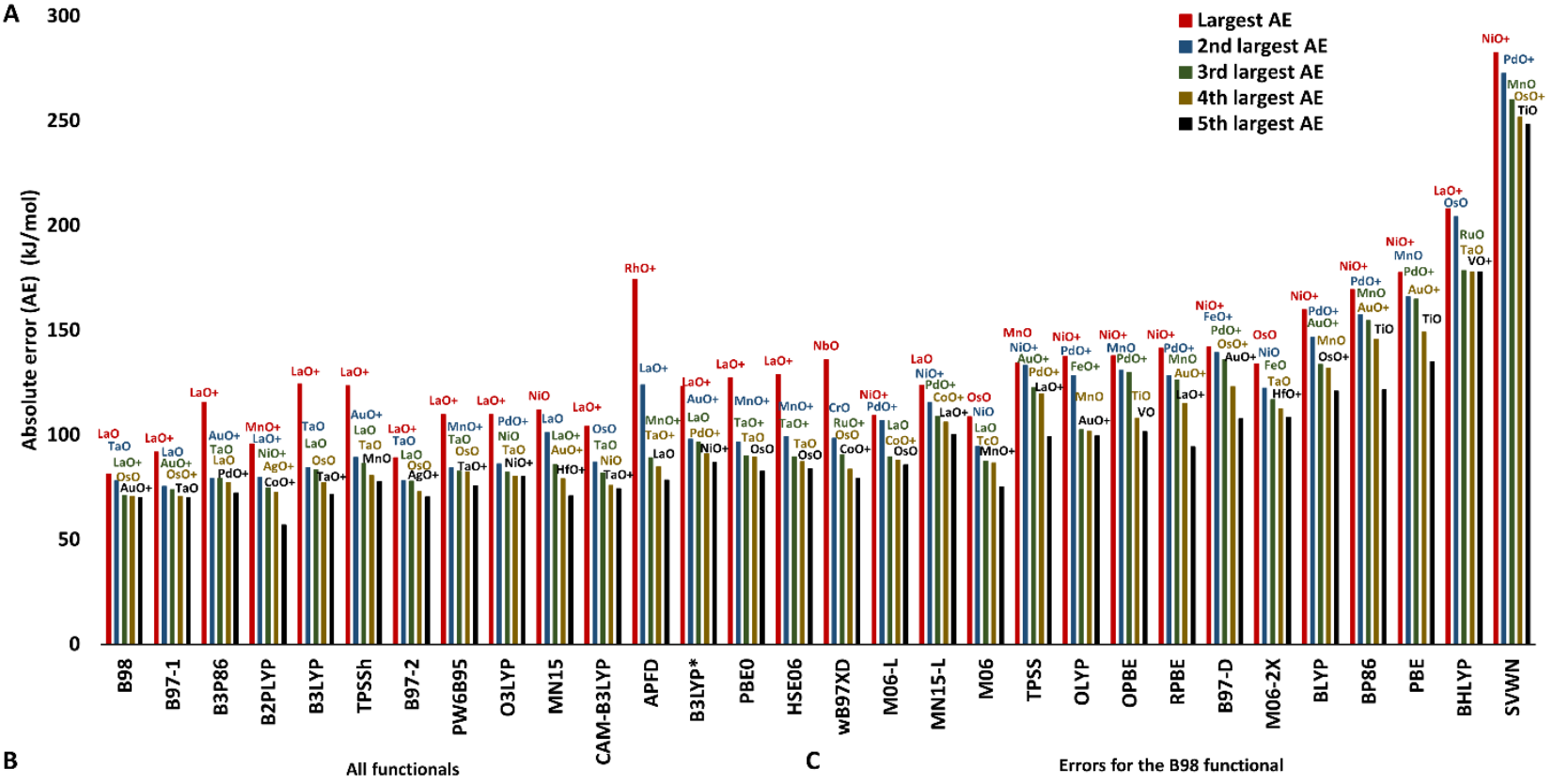

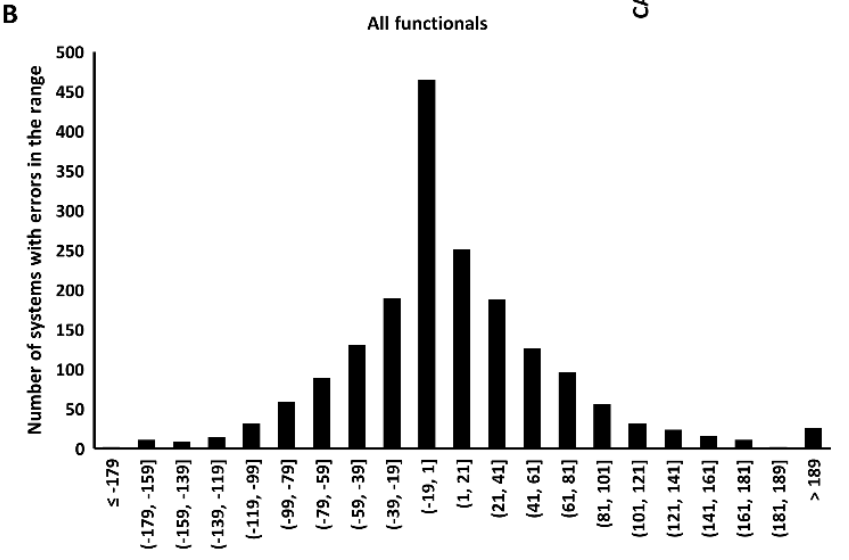

Signed error $(\mathrm{kJ} / \mathrm{mol})$

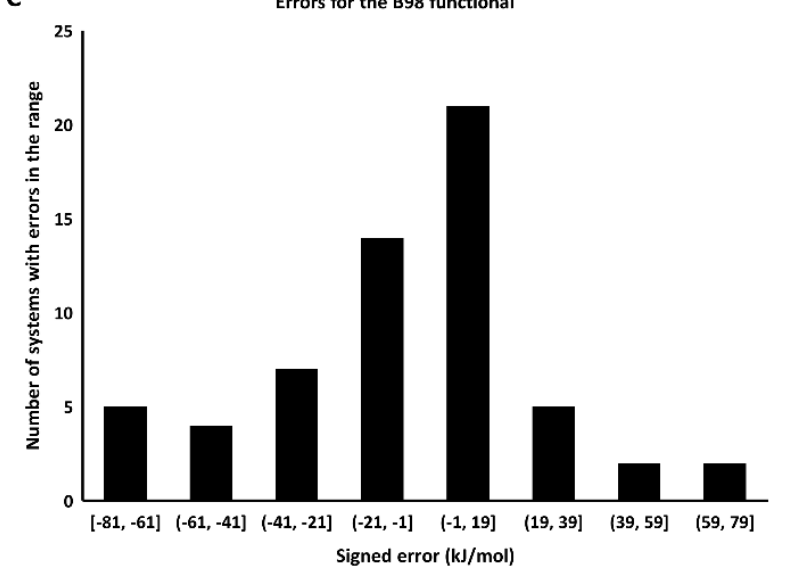

Figure 2. A) The five largest absolute errors (AE) for the 30 functionals of Table 1. Tabulated values available in Table S26. B) Distribution of errors for all 30 studied functionals. C) Distribution of errors for the B98 functional.

System dependencies and distributions of errors. To identify whether any systems cause particular problems, we compiled the systems with the five largest AEs for each functional, as summarized in Figure 2A, ordered by MAE (full data in Table S41). The most problematic experimental data were identified and replaced by alternative data in cases where several data exist, ${ }^{[30]}$ and the errors should therefore mainly indicate the failures of specific functionals to specific electronic structures, although some of the error remains due to uncertainties in the experimentally determined BDE values. ${ }^{[34]}$ The AEs of Figure $2 \mathrm{~A}$ range from 70 to $283 \mathrm{~kJ} / \mathrm{mol}$, 
and the most important general observation is that the severity of the pathological cases grows monotonically with the overall performance of the functional. Ten systems account for 118 of the 150 pathological cases of Figure 2A: $\mathrm{LaO}^{+}$(19 occurrences), $\mathrm{NiO}^{+}(14), \mathrm{PdO}^{+}(14), \mathrm{AuO}^{+}(13)$, $\mathrm{TaO}$ (13), $\mathrm{LaO}$ (12), OsO (12), $\mathrm{MnO}(9), \mathrm{MnO}^{+}(6)$ and $\mathrm{TaO}^{+}(6)$. For $\mathrm{LaO}^{+}$, no functional displays an AE smaller than $52 \mathrm{~kJ} / \mathrm{mol}$ (B97-D) indicating that none of the functionals describe this system well, assuming that the experimental value can be trusted. Since DFT does not have special problems with the valence-iso-electronic $\mathrm{YO}^{+}$and other neighboring systems, we however suspect that the experimental number could be uncertain by perhaps $30 \mathrm{~kJ} / \mathrm{mol}$ or so. Figure 2 B and Figure 2C show the distribution of the obtained errors for all functionals together and for the bestperforming functional B98. Both histograms clearly indicate that DFT-errors for a wide suite of functionals are approximately normal-distributed, which is an important observation and relates to the statistical significance and precision discussed in other places in the paper. The outlier in the total plot to the right in Figure 2B is due to the strongly over-binding LDA functional.

In order to test whether our results depend on the nature of the data set, we calculated the MSE, MAE, and STD also for subsets of the total data where we left out $\mathrm{LaO}^{+}$specifically, any one of the 10 groups (groups 3-12) and any one period (3d, 4d, or 5d). The errors obtained for these various subsets of data are summarized in Supporting information, Tables S28-S40. Leaving out $\mathrm{LaO}^{+}$from the analysis (Table $\mathbf{S 2 7}$ ) does not change the ranking of the top-3 functionals, the ranking changes in some cases by 1-2 positions for very similarly performing methods, and thus the uncertainty in the value of $\mathrm{LaO}^{+}$is not affecting the overall conclusions of our work. Similar rankings within a few positions are generally obtained by disregarding any group (Tables S28-S37), with the top-3 unaffected in all cases except group 9 where B2PLYP marginally enters top-3 at the expense of B3P86. Exclusion of any period (Tables S38-S40) affects the accuracy of some functionals: Disregarding the 3d metals (Table S38) puts B2PLYP and PW6B95 into top-3 instead of B98 and B97-1. Disregarding the 4d metals (Table S39) puts B97-2 in top-3 replacing B3P86. Disregarding the 5d metals (Table S40) also places B97-2 in the top 3 instead of B3P86. Exclusion 
of $5 \mathrm{~d}$ metals lowers the MAE for most functionals by up to $10 \mathrm{~kJ} / \mathrm{mol}$. Thus, the accuracy for the $5 \mathrm{~d}$ transition metals is generally lower than for the $3 \mathrm{~d}$ and $4 \mathrm{~d}$ metals, probably due to relativistic treatments. Similar period-wise errors are likely to exist in studies using less complete relativistic treatments, for example comparing $\mathrm{Pt}$ and $\mathrm{Pd} / \mathrm{Ni}$ catalysts. Except for this effect, general tendencies in performance are very robust to reasonable variations in the data set.

Figure S1 and Figure S2 show the MAE and MSE separately for the transition metal groups 3-12. The ranking of the functionals changes noticeably from group to group which is unsurprising for such small subsets of data, with generally six calculated errors (three neutral and three charged molecules), and only four and three errors for group 7 and 12 respectively (Table S1). However, most of the trends observed for the overall data set prevail for groups individually. Almost all groups are best described by hybrids with 10-20\% HF-exchange (or the double hybrid B2PLYP), in contrast to what is seen for some other ligands. ${ }^{[40]}$ The most notable exception is group 12 , for which the GGAs perform well. The best performing functional for group 6 is OPBE, but other GGAs still perform poorly and hybrids with 10-20\% HF exchange still perform very well for group 6 . The group-9 metals also stand out with the best performing functional (B3P86) having an MAE of only $9 \mathrm{~kJ} / \mathrm{mol}$ and generally very small MAEs for the best functionals. The experimental uncertainties are not smaller for group- 9 metals than for the overall data set. The best functionals perform well across all transition metal groups, showing no bias towards any $\mathrm{d}^{\mathrm{q}}$ configurations, despite the fact that the M-O BDEs change by many hundreds of $\mathrm{kJ} / \mathrm{mol}$ from very oxophilic early transition metals to very weakly binding late transition metals. Correspondingly, the GGA functionals such as PBE and RPBE widely used in theoretical catalysis perform poorly across all groups. 


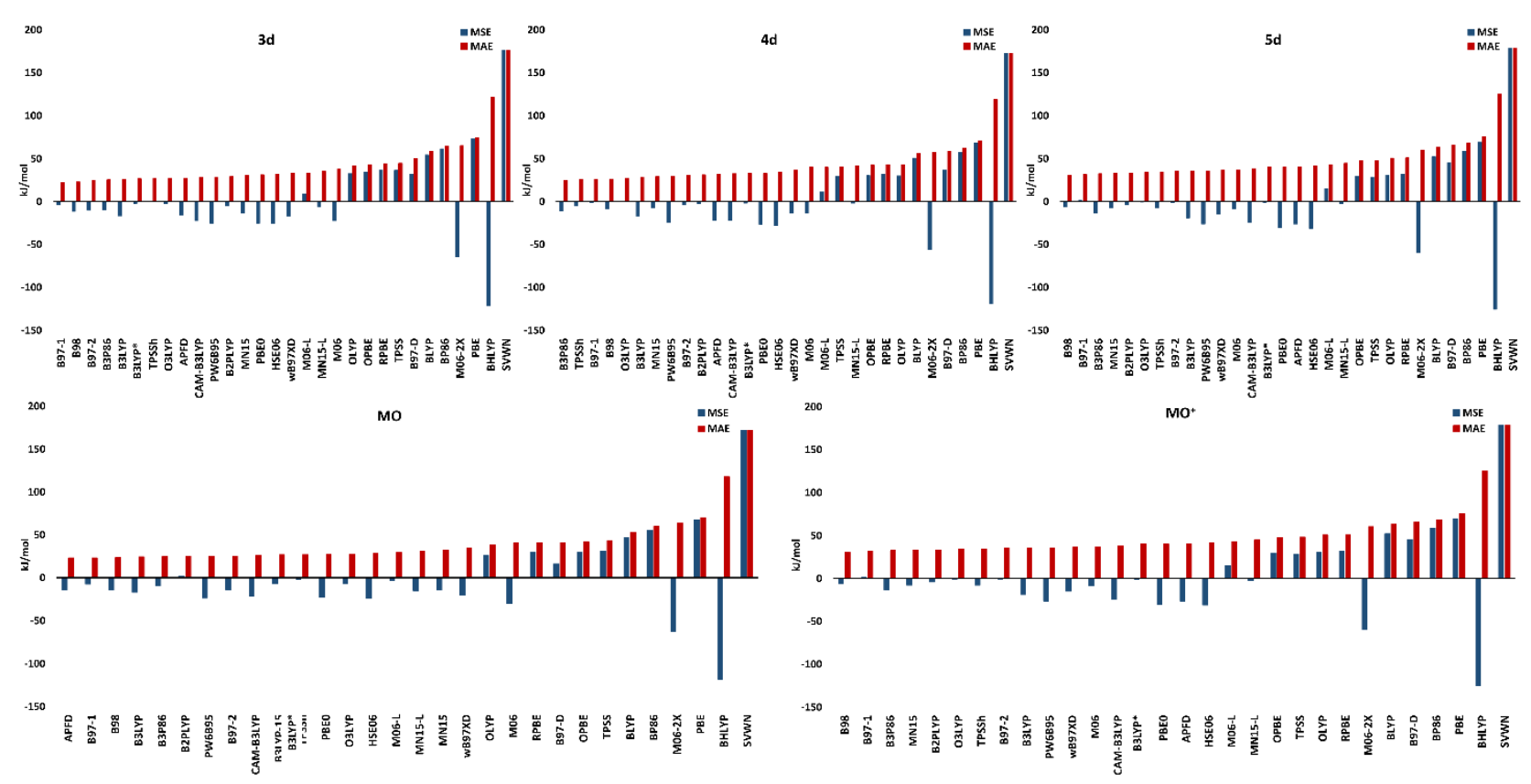

Figure 3. Mean absolute error (MAE) and mean signed error (MSE) for the 3d, 4d, 5d systems separately, the neutral MO species, and cationic $\mathrm{MO}^{+}$species.

Figure 3 shows the MAE and MSE when dividing into 3d, 4d and 5d systems. MAEs tend to increase somewhat when going from the $3 \mathrm{~d}$ to the $4 \mathrm{~d}$ and $5 \mathrm{~d}$ transition metals. As an example, the MAE for B97-1 for the $3 \mathrm{~d}$ metals is $22 \mathrm{~kJ} / \mathrm{mol}$, for the $4 \mathrm{~d}$ transition metals it is $26 \mathrm{~kJ} / \mathrm{mol}$ and for the $5 \mathrm{~d}$ transition metals it is $32 \mathrm{~kJ} / \mathrm{mol}$. This trend partly relates to the treatment of relativistic effects, which introduces an error on the between-period comparisons of approximately $5 \mathrm{~kJ} / \mathrm{mol}$, as shown previously using $\operatorname{CCSD}(\mathrm{T})$, because the spin orbit-coupling treatment of the all-electron scalar-relativist $3 \mathrm{~d}$ systems and the effective core potential-based $4 \mathrm{~d}$ and $5 \mathrm{~d}$ systems are not fully consistent $^{[30]}$; specifically, we expect (and see) that the $4 \mathrm{~d}$ and $5 \mathrm{~d}$ frozen-core systems have their spin-orbit coupling energy underestimated relative to the $3 \mathrm{~d}$ systems. The fact that the $5 \mathrm{~d}$ systems tend to be best described by the best-performing functionals is thus potentially a cancellation of a systematic error of $\sim 5 \mathrm{~kJ} / \mathrm{mol}$. Most studies in computational transition metal chemistry will tend to carry this between-period error with them, at best, if they treat relativistic corrections in this way as typically recommended. Most studies in theoretical catalysis consider the relativistic corrections at levels lower than this, in some cases ignoring spin-orbit coupling of some of the periods or scalar- 
relativistic effects of the $3 \mathrm{~d}$ systems, which will make errors substantially larger and of the order of $10-25 \mathrm{~kJ} / \mathrm{mol}$, adding to other errors in the study ${ }^{[30]}$.

Despite these uncertainties due to the relativistic treatment, hybrids with approximately 10$20 \%$ HF-exchange remain the most accurate for all three periods. Thus, the introduced errors arising from between-period comparisons, while affecting local rankings of functionals and thus making strong conclusions on overall performance unjustified, the general tendencies in the performance of types of functionals is very robust.

Figure 3 also shows the accuracy when the data is divided into the neutral MO species and the cationic $\mathrm{MO}^{+}$species. The neutral MO systems display a significantly lower MAE than the cationic $\mathrm{MO}^{+}$systems. As an example, B3LYP has a MAE of $24 \mathrm{~kJ} / \mathrm{mol}$ for the MO species while the MAE for the $\mathrm{MO}^{+}$species it is $36 \mathrm{~kJ} / \mathrm{mol}$. This trend is rather general for all functionals, where one functional APFD shows a very large variation in accuracy being the most accurate for the MO systems with an MAE of $23 \mathrm{~kJ} / \mathrm{mol}$ while for the $\mathrm{MO}^{+}$systems the MAE has risen to $40 \mathrm{~kJ} / \mathrm{mol}$, APFD now only the $16^{\text {th }}$ most accurate. For both neutral and cationic systems the hybrid-GGAs with $20 \%$ HF-exchange are still the most accurate.

DFT trend predictions for M-O bonds with different M. In addition to the errors analyzed above, which relate to overall accuracy and precision of the data groups, it is also important to evaluate the ability of DFT to describe relative values of BDEs as particularly relevant to computational studies where several metals are compared, e.g. when rationalizing the performance of different metals as catalysts for O-O bond activation. Figure 4 shows the linear relationship between computed and experimental BDEs for the four most accurate functionals B98, B97-1, B3P86 and B2PLYP. The slope, intercept, and $\mathrm{R}^{2}$ values are tabulated for all functionals in Table $\mathbf{S 4 2}$ and linear correlation plots for all functionals can be seen in Figures S3-S32. 
Generally, excellent correlation is observed for all functionals, showing $\mathrm{R}^{2}$ values from 0.94 to 0.98 (Table S42). The four functionals of Figure 4 have $\mathrm{R}^{2}$ values of $0.97-0.98$ and standard errors from the regression line of 33-37 kJ/mol. This implies that trend predictions are, on average, within $\approx 35 \mathrm{~kJ} / \mathrm{mol}$ of the experimental value for the four functionals of Figure 4 . The slopes vary in the interval $0.95-1.04$, indicating good scalability of DFT across regimes of weak and strong binding. For the best-performing functionals, the intersection with the y-axis varies from -9.0 (B98) to 23.2 (B2PLYP) $\mathrm{kJ} / \mathrm{mol}$, i.e. the functionals interpolate well to the zero-bonding limit. There is a small, surprising tendency for errors to be larger for the weakly bound systems with small BDEs, which we suspect is due to errors in the experimental data, since we expect DFT errors to scale with the magnitude of the computed values. Figure 4 illustrates the good practice of using DFT chemical energies only comparatively as error cancellations strengthen significance. ${ }^{[32]}$ The excellent behavior of DFT in terms of trend predictions is also shown along the $3 \mathrm{~d}, 4 \mathrm{~d}$, and $5 \mathrm{~d}$ groups in Figure S33, where CCSD(T) from previous work and experimental BDEs are compared to B98 as a representative example of an accurate functional reproducing excellently the trends and hump structure of the d-block M-O bonds. This tendency is interestingly true for all hybrids studied, but much less true for GGAs. Applications of DFT to chemical processes often involve regimes of both stronger and weaker binding modulated by surfaces or other ligands, and thus strong performance in both limits is essential for accurate theoretical catalysis. 

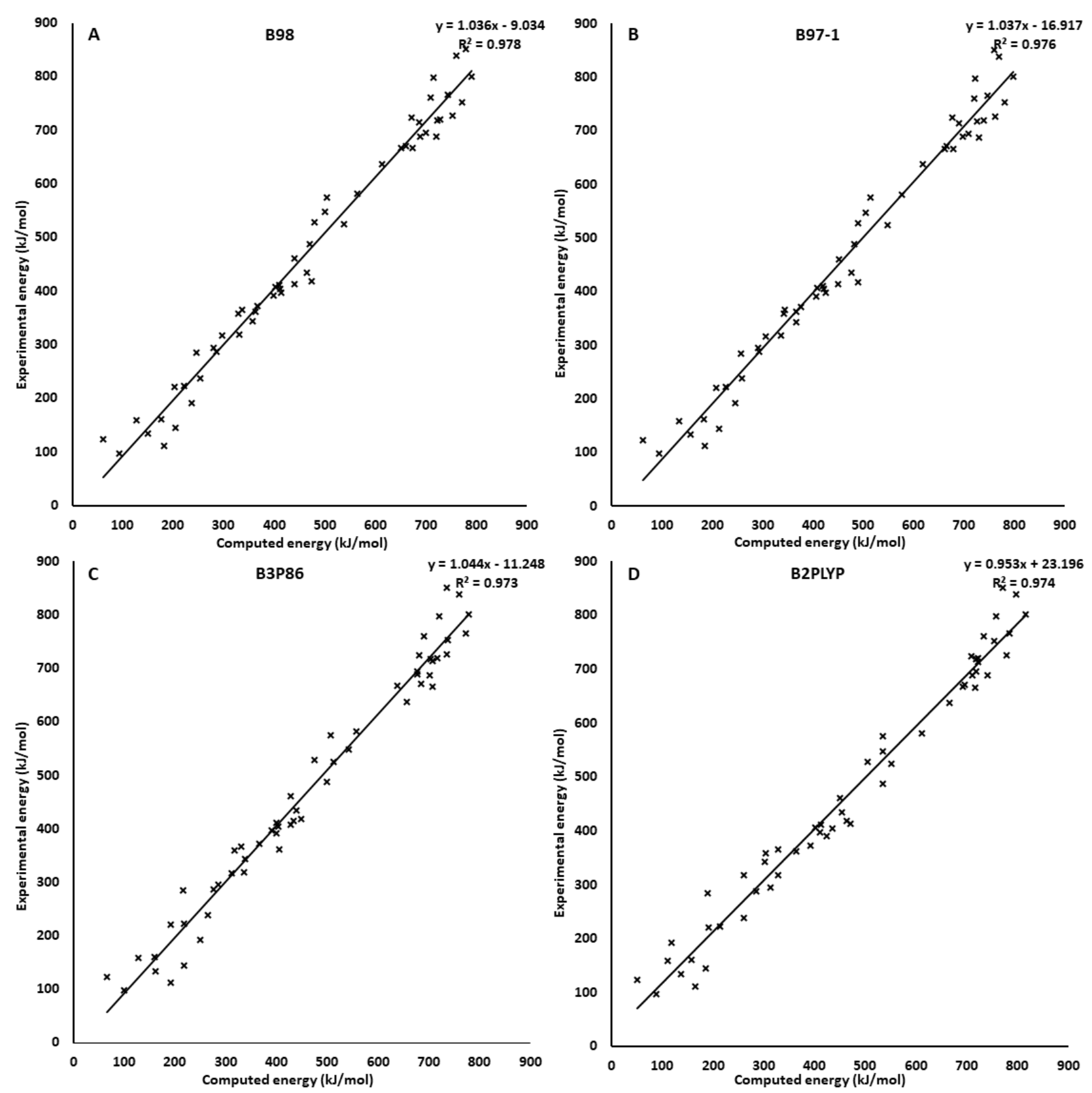

Figure 4. Linear correlation between experimental (Table 2) and computed BDEs (Tables S18S22) for the four functionals with the lowest MAE for all $60 \mathrm{MO}$ and $\mathrm{MO}^{+}$systems A) B98 B) B971 C) B3P86 D) B2PLYP.

Relation to previous work. This paper is as far we know the first to consider all diatomic transition metal oxides in their totality, giving a complete perspective on the performance of DFT for these systems, in particular by testing universality (in the definition "uniform accuracy"[100]) vs. variations due to group and period. A comparison to previous work on $\mathrm{MO}$ and $\mathrm{MO}^{+}$systems is however still of interest. 
Furche and Perdew ${ }^{[50]}$ computed the BDEs for nine neutral $3 \mathrm{~d}$ transition metal oxides Sc$\mathrm{Cu}$, with the functionals BP86, PBE, TPSS, B3LYP and TPSSh using a QZVP basis and ZPE corrections (summarized in Table S43). Results for $\mathrm{ScO}, \mathrm{CrO}, \mathrm{MnO}, \mathrm{FeO}, \mathrm{CoO}$, and $\mathrm{CuO}$ are in fair agreement with the computations of this work, with AEs less than $20 \mathrm{~kJ} / \mathrm{mol}$, close to the experimental uncertainty. However, for $\mathrm{TiO}, \mathrm{VO}$, and $\mathrm{NiO}$ there is substantial disagreement between the computed values with AEs up to $60 \mathrm{~kJ} / \mathrm{mol}$. The most notable difference in methodology is the neglect of relativistic corrections by Furche and Perdew and the smaller basis set for very electronegative, electron-rich oxygen. A comparison of the MAE compared to the experimental data can been seen in Table $\mathbf{S 4 4}$. Overall, the conclusions on relative performance are similar for the subset of data. The GGAs values of Furche \& Perdew tended to be more accurate than in our work, whereas B3LYP and TPPSh are equally accurate or slightly more accurate in our study.

Zhao \& Truhlar ${ }^{[46]}$ computed the BDEs of TiO, $\mathrm{MnO}$ and $\mathrm{CuO}$ with a QZVP basis using the TPSS, B3LYP, TPPSh, BLYP and B97-2 functionals (Table S45). AEs between 13 and 289 kJ/mol are observed relative to our computations, and generally the agreement is poor. Especially $\mathrm{CuO}$ calculated by TPSSh deviates by $289 \mathrm{~kJ} / \mathrm{mol}$. The treatment of relativistic effects and basis set cannot explain these differences. Based on the experimental data used and curated in this work, it would seem that some computations of the previous work ${ }^{[46]}$ have been performed on an excited state for example for $\mathrm{CuO}$, which was common before the protocol of spin annealing, which we used in this and our recent work $^{[30,39,40]}$.

Jensen et al. ${ }^{[20]}$ computed the BDEs for the ten neutral MO systems of Sc-Zn with a TZVP basis set and the B3LYP, PBE0, BP86, PBE and BLYP functionals (Table S46), ZPE corrections, and scalar-relativistic effects. The agreement is generally quite good with AEs of 16-46 kJ/mol across all functionals. The main exception is $\mathrm{TiO}$ where the $\mathrm{AE}$ is $342-349 \mathrm{~kJ} / \mathrm{mol}$. As has been established previously ${ }^{[30]}$ a new BDE value is appropriate and thus the old tabulated BDE for TiO of $372 \mathrm{~kJ} / \mathrm{mol}$ is much too low. Without this error, agreement is generally very good (Table S46). 
Finally, Rinaldo et al ${ }^{[47]}$ (Table S47) studied 18 of the 60 systems of this work, i.e. the diatomic neutral molecules from $\mathrm{ScO}-\mathrm{CuO}$ and the cationic diatomics of $\mathrm{ScO}^{+}-\mathrm{CuO}^{+}$using $\mathrm{B} 3 \mathrm{LYP}$ with a LACVP ${ }^{[101]}$ basis set on the metals and $6-31 G^{*}$ on oxygen. Good agreement is again seen with AEs only above $20 \mathrm{~kJ} / \mathrm{mol}$ for $\mathrm{NiO}, \mathrm{MnO}^{+}, \mathrm{CoO}^{+}$and $\mathrm{CuO}^{+}$(AEs of 31, 47, 22 and $24 \mathrm{~kJ} / \mathrm{mol}$ respectively), largely due to differences in basis set and relativistic treatment. The agreement indicates (but cannot guarantee) that the same lowest-energy configurations were used for all atoms and molecules in the two studies, something that is otherwise the cause of most discrepancy and difficulty for these types of systems.

\section{Conclusions}

Transition metal oxygen bond energies vary by many hundreds of $\mathrm{kJ} / \mathrm{mol}$ across the periods of the d-block, and theoretical catalysis and inorganic chemistry regularly uses DFT to study oxygen binding to transition metals across the groups and $3 \mathrm{~d}, 4 \mathrm{~d}$, and $5 \mathrm{~d}$ periods. Non-uniform accuracy across the d-block could substantially limit the predictions of theoretical catalysis comparing e.g. $\mathrm{Pd}$ and $\mathrm{Pt}$ (period-wise) or Fe and Ni (group-wise). To explore the universality (transferability) of DFT across all of the d-block, we benchmarked 30 diverse density functionals against the bond dissociation enthalpies (BDE) of the $30 \mathrm{MO}$ and $30 \mathrm{MO}^{+}$diatomic systems of all the $3 \mathrm{~d}, 4 \mathrm{~d}$, and $5 \mathrm{~d}$ metals, correcting for vibrational and relativistic effects.

We find that seven functionals, B98, B97-1, B3P86, B2PLYP, TPSSh, B3LYP, and B97-2, display mean absolute errors (MAE) $<30 \mathrm{~kJ} / \mathrm{mol}$ for the d-block as a whole, which is remarkably good considering the experimental uncertainty and performance of $\operatorname{CCSD}(\mathrm{T})$ for the same data set $^{[30]}$. However, we also find that many commonly used functionals such as PBE and RPBE overestimate $\mathrm{M}-\mathrm{O}$ bonding by $+30 \mathrm{~kJ} / \mathrm{mol}$ and display MAEs from $48-76 \mathrm{~kJ} / \mathrm{mol}$. RPBE and OPBE reduce the over-binding of PBE but remain very inaccurate. 
We show that there is a significant but modest linear relationship $\left(\mathrm{R}^{2}=0.46\right)$ between the precision and accuracy of DFT, i.e. inaccurate functionals such as PBE and RPBE tend to produce much larger random errors. We also show that there are interestingly substantial outliers from this tendency. Most notably, highly parameterized functionals commonly deviate from the relationship. We stress that both the accuracy and the precision, estimating the expected spread in computed outcome, is of major importance to accurate trend predictions as required in theoretical catalysis and inorganic chemistry. We show that there is a tendency for $5 \mathrm{~d}$ systems to be differently described than $4 \mathrm{~d}$ and $3 \mathrm{~d}$ systems, with an error of $5-10 \mathrm{~kJ} / \mathrm{mol}$, relating partly to the relativistic treatment. We expect this error to prevail also in the many studies in theoretical catalysis that routinely compare $5 \mathrm{~d}$ and $4 \mathrm{~d}$ systems with relativistic corrections less elaborate than used here. The $4 \mathrm{~d}$ and in particular the $5 \mathrm{~d}$ frozen-core systems may have their spin-orbit coupling energy underestimated relative to the 3d systems.

The best-performing hybrids all tend to have 10-30\% HF exchange, but we show that this requirement can be relaxed by double hybrids, with B2PLYP showing encouraging results. We note that uniform good accuracy across the d-block is one thing, the functional also needs to be accurate for diverse ligands binding to the metals. Considering previous results for metal-hydrogen bonds ${ }^{[39]}$, we can now conclude that chemical processes involving both $\mathrm{M}-\mathrm{O}$ and $\mathrm{M}-\mathrm{H}$ bond breaking or formation (e.g. transition metal catalyzed water oxidation, or oxygen reduction reactions) require advanced functionals such as double hybrids (B2PLYP), range-separated hybrids (CAMB3LYP), or meta hybrids (B98 or PW6B95), which uniquely show uniform accuracy and precision for both $\mathrm{M}-\mathrm{O}$ and $\mathrm{M}-\mathrm{H}$ bonds across the d-block.

Most functionals describe trends well, quantifying DFT's strength in relative predictions. Finally, we note that our benchmark study is relevant also to larger systems since, as shown previously ${ }^{[30]}$, the local M-O bonds dominate $\left(\mathrm{R}^{2} \sim 0.89\right)$ the $\mathrm{O}_{2}$ binding energies of full metal surfaces, as also expected from the fact that variations in cohesive energies (enthalpies of atomization of the metals) are up to an order of magnitude smaller than variations in M-O BDEs 
and $\mathrm{O}_{2}$ chemisorption energies, which puts an upper limit to the impact of metal-metal modulation effects on the local M-O bond at the metal surface.

\section{Acknowledgments}

We acknowledge the use of the High-Performance Computing Cluster at DTU.

\section{Supporting Information}

The Supporting information file contains the experimental BDEs and the computed BDEs, including all converged electronic energies and other parameters needed to compute the BDEs from Equation 1. The supporting information file also contains the tabulated values for all figures in the text and the tabulated values of statistical assessments referred to in the text. 


\section{References}

[1] J. E. Post, Proc. Natl. Acad. Sci. 1999, 96, 3447-3454.

[2] A. F. Buddington, D. H. Lindsley, J. Petrol. 1964, 5, 310-357.

[3] K. Misra, Understanding Mineral Deposits, Springer Science \& Business Media, 2012.

[4] D. G. Schulze, J. B. Dixon, Soil Mineral. with Environ. Appl. 2002, 1-35.

[5] J. P. Collman, R. Boulatov, C. J. Sunderland, L. Fu, Chem. Rev. 2004, 104, 561-588.

[6] E. I. Solomon, D. E. Heppner, E. M. Johnston, J. W. Ginsbach, J. Cirera, M. Qayyum, M. T. Kieber-Emmons, C. H. Kjaergaard, R. G. Hadt, L. Tian, Chem. Rev. 2014, 114, 3659-3853.

[7] P. R. O. De Montellano, Cytochrome P450: Structure, Mechanism, and Biochemistry, Springer Science \& Business Media, 2005.

[8] K. P. Kepp, Coord. Chem. Rev. 2017, 344, 363-374.

[9] A. Bielański, J. Haber, Catal. Rev. Sci. Eng. 1979, 19, 1-41.

[10] H. H. Kung, Transition Metal Oxides: Surface Chemistry and Catalysis, Elsevier, 1989.

[11] L. Liu, A. Corma, Chem. Rev. 2018, 118, 4981-5079.

[12] K. P. Kepp, Inorg. Chem. 2016, 55, 9461-9470.

[13] A. Sawa, Mater. today 2008, 11, 28-36.

[14] P. Poizot, S. Laruelle, S. Grugeon, L. Dupont, J. M. Tarascon, Nature 2000, 407, 496.

[15] C. Yuan, H. Bin Wu, Y. Xie, X. W. Lou, Angew. Chemie Int. Ed. 2014, 53, 1488-1504.

[16] Q. Liang, X. Wu, D. Weng, H. Xu, Catal. Today 2008, 139, 113-118.

[17] M. Ni, M. K. H. Leung, D. Y. C. Leung, K. Sumathy, Renew. Sustain. Energy Rev. 2007, 11, $401-425$. 
[18] R. A. Periana, D. J. Taube, S. Gamble, H. Taube, T. Satoh, H. Fujii, Science (80-. ). 1998, $280,560-564$.

[19] K. A. Joergensen, Chem. Rev. 1989, 89, 431-458.

[20] K. P. Jensen, B. O. Roos, U. Ryde, J. Chem. Phys. 2007, 126, 014103.

[21] C. W. Bauschlicher, P. Maitre, Theor. Chim. Acta 1995, 90, 189-203.

[22] P. E. M. Siegbahn, Chem. Phys. Lett. 1993, 201, 15-23.

[23] Y. Gong, M. Zhou, L. Andrews, Chem. Rev. 2009, 109, 6765-6808.

[24] A. J. Merer, Annu. Rev. Phys. Chem. 1989, 40, 407-438.

[25] X.-F. Yang, A. Wang, B. Qiao, J. Li, J. Liu, T. Zhang, Acc. Chem. Res. 2013, 46, 1740-1748.

[26] S. Sun, G. Zhang, N. Gauquelin, N. Chen, J. Zhou, S. Yang, W. Chen, X. Meng, D. Geng, M. N. Banis, Sci. Rep. 2013, 3, 1775.

[27] R. Hefferlin, R. Campbell, D. Gimbel, H. Kuhlman, T. Cayton, J. Quant. Spectrosc. Radiat. Transf. 1979, 21, 315-336.

[28] P. B. Armentrout, L. F. Halle, J. L. Beauchamp, J. Am. Chem. Soc. 1981, 103, 6501-6502.

[29] A. J. Bridgeman, J. Rothery, J. Chem. Soc. Dalt. Trans. 2000, 211-218.

[30] K. A. Moltved, K. P. Kepp, J. Phys. Chem. C 2019, 0, acs.jpcc.9b04317.

[31] I. Toyoshima, G. A. Somorjai, Catal. Rev. 1979, 19, 105-159.

[32] K. P. Kepp, Coord. Chem. Rev. 2013, 257, 196-209.

[33] Y. A. Aoto, A. P. de Lima Batista, A. Köhn, A. G. S. de Oliveira-Filho, J. Chem. Theory Comput. 2017, 13, 5291-5316.

[34] X. Xu, W. Zhang, M. Tang, D. G. Truhlar, J. Chem. Theory Comput. 2015, 11, 2036-2052. 
[35] J. Shee, B. Rudshteyn, E. J. Arthur, S. Zhang, D. R. Reichman, R. A. Friesner, J. Chem. Theory Comput. 2019, acs.jctc.9b00083.

[36] Z. Fang, M. Vasiliu, K. A. Peterson, D. A. Dixon, J. Chem. Theory Comput. 2017, 13, 10571066.

[37] L. Cheng, J. Gauss, B. Ruscic, P. B. Armentrout, J. F. Stanton, J. Chem. Theory Comput. 2017, 13, 1044-1056.

[38] M. D. Morse, Acc. Chem. Res. 2019, 52, 119-126.

[39] K. A. Moltved, K. P. Kepp, J. Phys. Chem. A 2019, acs.jpca.9b02367.

[40] K. A. Moltved, K. P. Kepp, J. Chem. Theory Comput. 2018, 14, 3479-3492.

[41] K. P. Kepp, Commun. Chem. 2018, 1, 63.

[42] C. Hättig, D. P. Tew, A. Köhn, 2010.

[43] D. G. Liakos, M. Sparta, M. K. Kesharwani, J. M. L. Martin, F. Neese, J. Chem. Theory Comput. 2015, 11, 1525-1539.

[44] Y. Nakao, K. Hirao, T. Taketsugu, J. Chem. Phys. 2001, 114, 7935-7940.

[45] Y. Nakajima, J. Seino, H. Nakai, Chem. Phys. Lett. 2017, 673, 24-29.

[46] Y. Zhao, D. G. Truhlar, J. Chem. Phys. 2006, 124, 224105.

[47] D. Rinaldo, L. Tian, J. N. Harvey, R. A. Friesner, J. Chem. Phys. 2008, 129, 164108.

[48] P. E. M. Siegbahn, M. R. A. Blomberg, Chem. Rev. 2000, 100, 421-438.

[49] R. A. Van Santen, I. Tranca, Phys. Chem. Chem. Phys. 2016, 18, 20868-20894.

[50] F. Furche, J. P. Perdew, J. Chem. Phys. 2006, 124, 044103.

[51] 2012, available from http://www.turbomole.com. 
[52] M. J. Frisch, G. W. Trucks, H. B. Schlegel, G. E. Scuseria, M. A. Robb, J. R. Cheeseman, G. Scalmani, V. Barone, G. A. Petersson, H. Nakatsuji, et al., 2016, DOI .

[53] A. Kramida, Y. Ralchenko, J. Reader, NIST ASD Team (2018), "NIST Atomic Spectra Database (ver. 5.5.6), [Online],” DOI https://doi.org/10.18434/T4W30F, 2018.

[54] F. Weigend, R. Ahlrichs, Phys. Chem. Chem. Phys. 2005, 7, 3297-3305.

[55] T. H. Dunning, J. Chem. Phys. 1989, 90, 1007-1023.

[56] K. P. Kepp, J. Phys. Chem. A 2017, 121, 9092-9098.

[57] A. Austin, G. A. Petersson, M. J. Frisch, F. J. Dobek, G. Scalmani, K. Throssell, J. Chem. Theory Comput. 2012, 8, 4989-5007.

[58] S. Grimme, J. Chem. Phys. 2006, 124, 34108.

[59] P. J. Stephens, F. J. Devlin, C. F. Chabalowski, M. J. Frisch, J. Phys. Chem. 1994, 98, 1162311627.

[60] C. Lee, W. Yang, R. G. Parr, Phys. Rev. B 1988, 37, 785-789.

[61] A. D. Becke, J. Chem. Phys. 1993, 98, 5648-5652.

[62] A. D. Becke, Phys. Rev. A 1988, 38, 3098-3100.

[63] J. P. Perdew, Phys. Rev. B 1986, 33, 8822-8824.

[64] F. A. Hamprecht, A. J. Cohen, D. J. Tozer, N. C. Handy, J. Chem. Phys. 1998, 109, 62646271.

[65] P. J. Wilson, T. J. Bradley, D. J. Tozer, J. Chem. Phys. 2001, 115, 9233-9242.

[66] S. Grimme, J. Comput. Chem. 2006, 27, 1787-1799.

[67] H. L. Schmider, A. D. Becke, J. Chem. Phys. 1998, 108, 9624-9631.

[68] A. D. Becke, J. Chem. Phys. 1993, 98, 1372-1377. 
[69] T. Yanai, D. P. Tew, N. C. Handy, Chem. Phys. Lett. 2004, 393, 51-57.

[70] A. V Krukau, O. A. Vydrov, A. F. Izmaylov, G. E. Scuseria, J. Chem. Phys. 2006, 125, 224106.

[71] A. F. Izmaylov, G. E. Scuseria, M. J. Frisch, J. Chem. Phys. 2006, 125, 104103.

[72] T. M. Henderson, A. F. Izmaylov, G. Scalmani, G. E. Scuseria, J. Chem. Phys. 2009, 131, 44108.

[73] J. Heyd, G. E. Scuseria, M. Ernzerhof, J. Chem. Phys. 2006, 124, 219906.

[74] J. Heyd, J. E. Peralta, G. E. Scuseria, R. L. Martin, J. Chem. Phys. 2005, 123, 174101.

[75] J. Heyd, G. E. Scuseria, J. Chem. Phys. 2004, 120, 7274-7280.

[76] J. Heyd, G. E. Scuseria, J. Chem. Phys. 2004, 121, 1187-1192.

[77] Y. Zhao, D. G. Truhlar, Theor. Chem. Acc. 2008, 120, 215-241.

[78] Y. Zhao, D. G. Truhlar, J. Chem. Phys. 2006, 125, 194101.

[79] H. S. Yu, X. He, S. L. Li, D. G. Truhlar, Chem. Sci. 2016, 7, 5032-5051.

[80] H. S. Yu, X. He, D. G. Truhlar, J. Chem. Theory Comput. 2016, 12, 1280-1293.

[81] A. J. Cohen, N. C. Handy, Mol. Phys. 2001, 99, 607-615.

[82] N. C. Handy, A. J. Cohen, Mol. Phys. 2001, 99, 403-412.

[83] A. J. Cohen, N. C. Handy, Chem. Phys. Lett. 2000, 316, 160-166.

[84] J. P. Perdew, K. Burke, M. Ernzerhof, Phys. Rev. Lett. 1996, 77, 3865.

[85] C. Adamo, V. Barone, J. Chem. Phys. 1999, 110, 6158-6170.

[86] Y. Zhao, D. G. Truhlar, J. Phys. Chem. A 2005, 109, 5656-5667.

[87] B. Hammer, L. B. Hansen, J. K. Nørskov, Phys. Rev. B 1999, 59, 7413. 
[88] J. C. Slater, Quantum Theory of Molecular and Solids. Vol. 4: The Self-Consistent Field for Molecular and Solids, McGraw-Hill, New York, 1974.

[89] S. H. Vosko, L. Wilk, M. Nusair, Can. J. Phys. 1980, 58, 1200-1211.

[90] V. N. Staroverov, G. E. Scuseria, J. Tao, J. P. Perdew, J. Chem. Phys. 2003, 119, 1212912137.

[91] J.-D. Chai, M. Head-Gordon, Phys. Chem. Chem. Phys. 2008, 10, 6615-6620.

[92] W. Jiang, M. L. Laury, M. Powell, A. K. Wilson, J. Chem. Theory Comput. 2012, 8, 41024111.

[93] E. I. Ioannidis, H. J. Kulik, J. Phys. Chem. A 2017, 121, 874-884.

[94] K. P. Jensen, J. Cirera, J. Phys. Chem. A 2009, 113, 10033-10039.

[95] K. P. Kepp, Inorg. Chem. 2016, 55, 2717-2727.

[96] O. S. Siig, K. P. Kepp, J. Phys. Chem. A 2018, 122, 4208-4217.

[97] K. Jensen, U. Ryde, J. Phys. Chem. A 2003, 155, 7539-7545.

[98] K. P. Jensen, Inorg. Chem. 2008, 47, 10357-65.

[99] K. Duanmu, D. G. Truhlar, J. Chem. Theory Comput. 2017, 13, 835-842.

[100] K. P. Kepp, Phys. Chem. Chem. Phys. 2018, 20, 7538-7548.

[101] P. J. Hay, W. R. Wadt, J. Chem. Phys. 1985, 82, 270-283. 


\section{Table of content text}

We explored the ability of 30 density functionals to describe all bond enthalpies of the $30 \mathrm{MO}$ and $30 \mathrm{MO}^{+}$3d, 4d, and 5d systems. Some functionals (B98, B97-1, B2PLYP, and TPSSh) display errors below $30 \mathrm{~kJ} / \mathrm{mol}$, but performance varies greatly. We analyze the failure and success, accuracy and precision, as a first step towards accurate DFT for M-O bonds as required for theoretical catalysis. 